\title{
POPULATION STRUCTURE AND POLYMORPHISM \\ IN THE SLAVE-MAKING ANT \\ HARPAGOXENUS AMERICANUS (EMERY)
}

(HYMENOPTERA: FOR MICIDAE)

By Alfred Buschinger ${ }^{1}$ And Thomas M. Alloway ${ }^{2}$

Fachbereich Biologie, Institut für Zoologie,

der Technischen Hochschule, D6100 Darmstadt, Schnittspahnstr. 3; and Erindale College, University of Toronto,

Mississauga, Ontario, L5L 1C6, Canada

\section{INTRODUCTION}

The biology of the slave-making ant, Harpagoxenus americanus, has been studied by several previous investigators. Creighton (1927, 1929) described slave raids and performed some experiments on colony foundation. Wesson (1939) provided a classic account of numerous aspects of the natural history of $H$. americanus including its distribution, colony demography, hibernation, brood development, and its colony-foundation, mating, and slave-raiding behaviours. Alloway (in press) provides a detailed account of its raiding behaviour in comparison to that of the closely related, but more primitive, species Leptothorax duloticus.

Wesson (1939) found that, in addition to a rather small proportion of "normal" queenright colonies, there are many queenless "branch colonies" which sometimes contained apparently fertile "gynecoid" workers. Moreover, he observed the formation of such "branch colonies" as a consequence of slave raids which occurred late in the raiding season. Previously, Sturtevant (1927) had dissected americanus workers and found that they typically have 6 ovarioles and "a sac arising from the anterior end of the common oviduct" which he interpreted as being a seminal receptacle. Sturtevant also found some workerlike individuals with rudimentary ocelli and presumed that $H$. americanus, like the European $H$. sublaevis, has ergatoid queens. However, Wesson (1939) wrote that he had

\footnotetext{
${ }^{1}$ Supported by a grant from the Deutsche Forschungsgemeinschaft.

${ }^{2}$ Supported by Grant A0301 from the National Research Council of Canada.

Manuscript received by the editor April 27, 1978.
} 
failed to note any "ergatoids such as occur with European $H$. sublaevis." Nevertheless, Creighton (1950, p. 281), comparing $H$. americanus with $H$. canadensis and $H$. sublaevis, stated that in americanus "the ergatoid female is rarely produced."

In a recent study (Buschinger \& Alloway, in press), we demonstrated that in all probability there are no ergatoid queens at all in H. canadensis. In contrast, although "normal" full queens occur occasionally in $H$. sublaevis, the usual reproductive female in this species is an ergatoid form which closely resembles the worker caste in its external morphology. Moreover, polymorphism among reproductive females is genetically mediated in $H$. sublaevis (Buschinger, 1975, 1978, in press). Thus, the main objective of the present study was to determine whether ergatoid queens analogous to those found in $H$. sublaevis occur in $H$. americanus and, if so, what role they play. We especially wondered whether they might be the usual reproductives in the numerous "branch colonies" that lack a dealate full queen.

\section{MATERIAL AND METHODS}

Colonies of $H$. americanus were collected from various localities in the regional municipalities of Halton and Peel in southern Ontario, Canada. A few additional colonies were found near Cleveland and Ashtabula, Ohio, in the United States. Most of the colonies were nesting in old hollow acorns and hickory nuts lying on the ground. The colonies were removed from their nests using an aspirator either immediately in the field or later in the laboratory. Colonies whose broods consisted only of larvae and prepupae at the time of collection were kept alive in the laboratory for a few weeks to determine the sex and caste of the Harpagoxenus pupae that were produced. Some of the Harpagoxenus queens, all intermorphs, and most of the Harpagoxenus workers were dissected using a method which we have described fully elsewhere (Buschinger \& Alloway, in press).

\section{RESULTS}

1. Population data.

No effort was made to determine the ratio of Harpagoxenus to host-species colonies or the number of colonies per unit of area. Both variables fluctuate widely and depend upon a large number 
Table I. Occurrence of Lepothorax longispinosus and L. ambiguus as host species in colonies of $H$. americanus.

\begin{tabular}{lccc}
\hline $\begin{array}{c}\text { H. americanus } \\
\text { colonies }\end{array}$ & L. longispinosus & $\begin{array}{c}\text { with slave species } \\
\text { L. ambiguus }\end{array}$ & L. Long. + L. amb. \\
\hline incipient & 2 & - & 1 \\
queenright & 12 & - & 1 \\
queenless & 13 & 4 & 6
\end{tabular}

of factors such as the type of vegetation, surface drainage, the distribution of habitable nesting sites, etc. Sturtevant (1927) recorded an infestation rate of $13 \%$ for $H$. americanus (i.e. 17 americanus colonies to 132 colonies of one of its three host species, Leptothorax curvispinosus Mayr). In the areas where we collected our material, the host species were Leptothorax ambiguus Emery and L. longispinosus Roger. Although ambiguus was generally the more abundant of the two host species in acorn and hickory-nut nests, longispinosus was more frequently enslaved (Table I). These data suggest that colony-founding Harpagoxenus queens preferentially seek out longispinosus colonies but that established Harpagoxenus colonies, especially the so-called "branch colonies," raid the nests of both hosts.

Our material consisted of a total of 41 Harpagoxenus colonies or "branch colonies" in the sense of Wesson (1939). Thirteen "primary colonies" contained a dealate full Harpagoxenus queen and from 1 to 8 Harpagoxenus workers. The average number of Harpagoxenus workers in these colonies was 3.0. Three incipient colonies contained only a Harpagoxenus queen, several host-speices workers, and a brood which consisted of Harpagoxenus worker pupae or larvae which developed into Harpagoxenus worker pupae. The 25 "branch colonies" lacked a dealate full queen but contained from 1 to 9 Harpagoxenus workers (with an average of 2.8), a variable number of host-species workers, and a brood. Six of these "branch colonies" produced only male pupae of the parasite species; but the rest yielded female, worker, and male pupae of the parasite species. In one acorn which contained no adult Harpagoxenus when it was collected, there were nevertheless Harpagoxenus male, female, and worker pupae which were being attended by several longispinosus workers. Apparently, the Harpagoxenus adults had 
either died or were away for some reason (perhaps on a raid) when their nest was collected. Finally, we made one quite peculiar observation. We found a dealate Harpagoxenus queen crawling around on the outside of an acorn which contained 3 Harpagoxenus workers, several longispinosus slaves, and a brood. After collecting the queen and the "colony" together in a vial, the Harpagoxenus queen was heavily mutilated by the Harpagoxenus workers, thus indicating that the queen and the workers did not belong together. Dissection revealed that the queen was an inseminated, egg-laying individual and that all 3 of the workers in the nest were completely sterile. In all probability this collection represents a newly founded Harpagoxenus colony that had been raided by workers of another Harpagoxenus colony.

\section{Dissections}

Dealate queens: The only dealate females from 8 colonies and both dealate females from a single colony which contained 2 such individuals were dissected. All 10 females had 6 ovarioles and a spermatheca. One of the females from the two-queen colony had short ovarioles that contained no developing eggs, and an empty spermatheca. However, the other 9 individuals were functional colony queens, individuals with receptacula filled with sperm and ovarioles which were about their total body length and which contained eggs in different stages of growth and corpora lutea.

Intermorphs: In 6 different colonies ( 2 queenright colonies and 4 "branch colonies"), we found a total of 6 individuals that were morphologically intermediate between worker and full queens and which could thus be regarded as intermorphs. These individuals had more or less well developed ocelli on their heads and several distinct sclerites on the alitrunk. Workers lack these structures. All of these intermorphs except one had 6 short, empty ovarioles like those of a virgin queen. None of them had a spermatheca. One individual had ovarioles which were about as long as the gaster and which contained developing oocytes and corpora lutea. These data indicate that $H$. americanus intermorphs have a reproductive function which cannot be distinguished from that of ordinary workers. Although they cannot be inseminated, they do sometimes become egg-layers.

Workers: We dissected a total of 91 workers, 28 from 8 queenright colonies and 63 from 22 "branch colonies" which contained 
Table II: Numbers of fertile and sterile workers in queenright and queenless colonies.

\begin{tabular}{|c|c|c|c|c|c|c|c|}
\hline \multirow{2}{*}{$\begin{array}{c}\text { Colony } \\
\text { no. }\end{array}$} & \multirow[t]{2}{*}{ queen } & \multicolumn{3}{|c|}{ workers and intermorphs (I) } & \multirow{2}{*}{\multicolumn{2}{|c|}{$\begin{array}{c}\text { Harpagoxenus } \\
\text { of } \neq \\
\text { produced }\end{array}$}} & \multirow{2}{*}{$\begin{array}{l}\text { date of } \\
\text { collection }\end{array}$} \\
\hline & & sterile & $\begin{array}{l}\text { with growing } \\
\text { oocytes }\end{array}$ & $\begin{array}{l}\text { with grow. } 00 \mathrm{c} \text {. } \\
\text { and } \\
\text { corpora lutea }\end{array}$ & & & \\
\hline 1 & 1 & - & 3 & 1 & $0 \%$ & $\forall$ & VI $-12-77$ \\
\hline 2 & 1 & 1 & 2 & - & o 7 & & VI $-12-77$ \\
\hline 3 & 1 & 3 & - & - & 07 & $\forall$ & VI $-12-77$ \\
\hline 4 & 1 & 8 & - & - & & $\forall$ & VI $-13-77$ \\
\hline 5 & 1 & 1 & - & - & & 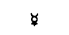 & VI-24-77 \\
\hline 6 & 1 & 2 & - & - & & $4 \%$ & VI-16-77 \\
\hline 7 & 1 & 4 & - & - & & $\forall$ & VII $-17-77$ \\
\hline 8 & - & 1 & - & - & 4047 & 27 & VI-12-77 \\
\hline 9 & - & $1(\mathrm{I})$ & 1 & - & 2027 & 27 & VI-12-77 \\
\hline 10 & - & 1 & - & - & & $17 \nsucceq$ & VI $-24-77$ \\
\hline 11 & - & 2 & 1 & - & 1817 & 78 & VI-16-77 \\
\hline 12 & - & 2 & 1 & - & 07 & $\forall$ & VI-22-77 \\
\hline 13 & - & - & - & 1 & 8 & $\forall$ & VII $-1-77$ \\
\hline 14 & - & - & 4 & $4+1(I)$ & 11017 & 8 & VI-12-77 \\
\hline 15 & - & - & - & 1 & $50^{\circ}$ & $4 \xi$ & VI-14-77 \\
\hline 16 & - & 2 & - & 3 & $70^{\circ}$ & & VI-14-77 \\
\hline 17 & - & - & 3 & 1 & $100^{\circ}$ & 18 & VI $-22-77$ \\
\hline 18 & - & - & - & 1 & & 48 & VI $-24-77$ \\
\hline 19 & - & - & 1 & 1 & $340^{\circ} 17$ & & VI $-27-77$ \\
\hline 20 & - & 3 & - & 1 & 108 & 2 & VII $-1-77$ \\
\hline 21 & - & - & 2 & $1(I)$ & $150^{\circ}$ & & VI-16-77 \\
\hline 22 & - & - & - & 1 & $110^{\circ}$ & & VI-22-77 \\
\hline 23 & - & - & - & 1 & $\delta$ & & VI-27-77 \\
\hline 24 & - & 1 & 3 & 5 & $100^{\circ}$ & & VII-1-77 \\
\hline 25 & - & 2 & - & 2 & 520 & & VII- $1-77$ \\
\hline
\end{tabular}

+) Numbers are indicated where the production could be completely recorded

no dealate queen. None of the workers had a spermatheca, but most of them had a rather large number of ovarioles. More specifically, we found 2 workers with 2 ovarioles, 1 with 3,6 with 5 , 81 with 6 , and 1 with 7 . Thus, most workers have the same number of ovarioles as queens. About half (45) the workers had short, thin ovarioles that contained no developing oocytes. These individuals were completely sterile. However, the other 46 workers manifested varying degrees of fertility. A total of 22 individuals possessed ovarioles containing white oocytes (a fact indicating that yolk has been deposited in the growing eggs); and 24 workers had actually begun to lay eggs, as indicated by the fact that there were 
corpora lutea in the bases of their ovarioles. The numbers of workers manifesting different degrees of fertility are shown in Table II for a selection of 25 typical colonies.

An examination of Table II reveals two facts which are especially noteworthy. First, workers with growing oocytes in their ovarioles and workers that have actually begun to lay eggs sometimes occur in queenright colonies (cf. Colonies 1 and 2 in Table II). One is tempted to speculate that these fertile workers are especially likely to found "branch colonies." However, no firm conclusion in this regard can be reached. Fertile workers also occur occasionally in queenright colonies of $H$. sublaevis (Buschinger \& Winter, 1978) and $H$. canadensis (Buschinger \& Alloway, in press), even though neither of these latter species appears to produce "branch colonies" of the kind seen in H. americanus. Second, some "branch colonies" which lacked a fully fertile worker (cf. Colonies $8,9,11$, and 12 in Table II) nevertheless produced Harpagoxenus males, queens, and workers. This latter fact, the fact that workers never possess a spermatheca, and the fact that most of the "branch colonies" which contained fertile workers produced only (cf. Colonies 16, 21, 22, 23, 24, 25 in Table II) or preferably (cf. Colonies 13, 14, 15, 17, 19, 20 in Table II) males of the parasite species combine to suggest that the queens and workers produced in "branch colonies" may never be the offspring of egg-laying workers. Thus, instead of assuming that $H$. americanus workers possess the highly unusual ability to produce female offspring parthenogenically (an assumption made by Wesson, 1939), we speculate that all workers and queens produced in branch colonies may be derived from female larvae which are carried over to the "branch colony" nest at the time of its initial occupation by $H$. americanus workers. In this connection, we stress that our data regarding the frequency of production of males, queens, and workers in branch colonies agree closely with those of Wesson (1939).

\section{DISCUSSION}

The main result of the present study is our failure to confirm the assumption (Sturtevant, 1927; Creighton, 1950) that $H$. americanus produces true ergatoid queens (workerlike individuals which possess a spermatheca, can be inseminated, and thus can lay fertilized eggs and function as colony queens). We suspect that the organ 
which Sturtevant interpreted as being the spermatheca in the $H$. americanus workers that he dissected was in fact the Dufour's gland. Thus, in H. americanus as in H. canadensis (Buschinger \& Alloway, in press), only the initially alate full queens possess a spermatheca and are capable of being inseminated. In this respect, both North American species differ radically from the European $H$. sublaevis in which true ergatoid queens are very common (Buschinger, 1975, 1978 , in press).

$H$. americanus populations consist of both monogynous, queenright "primary colonies" and queenless "branch colonies." In most locations, the "branch colonies" outnumber the "primary colonies" by a ratio of approximately $2: 1$. In accordance with the observations of Wesson (1939), we assume that the "primary colonies" are founded by single, newly fecundated $H$. americanus queens which penetrate small host-species colonies, usurp the place of the host queens, and begin to lay eggs. A first brood of americanus workers is then reared with the assistance of host workers. Subsequently, the supply of host workers is augmented by slave raids in which both the americanus workers and their slaves participate (Wesson, 1939; Alloway, in press). Late in the summer, some of these raids terminate in the formation of "branch colonies" by some of the americanus workers and their slaves (Wesson, 1939). However, despite Wesson's failure to observe the phenomenon in the laboratory, we suggest that, in the process of forming "branch colonies," the americanus workers and their slaves carry across a certain number of americanus larvae from the "primary colony" to their new nest. Most of these larvae mature to become workers, alate queens, and males the next summer. At the same time, one or more of the "branch colony" workers become fertile and begin laying eggs which develop into males during subsequent years. However, a few of the female larvae from the "primary colony" may undergo an additional hibernation before maturing to become queens or workers, a process which would explain Wesson's (1939) observation that "branch colonies" occasionally produce small numbers of queens and workers even in the second year in the laboratory. Such double hibernations are known to occur in Harpagoxenus sublaevis and its host species (Buschinger, 1973). Although we cannot definitely rule out the parthenogenic production of females in $H$. americanus, our supposition that the phenomenon does not occur affords (in addition to the advantage of simplicity) an ex- 
planation of our observations that (a) workers and queens are produced most abundantly in "branch colonies" which possess no fully functional egg-laying worker at all and (b) "branch colonies" that possess one or more egg-laying workers produce only or preferably males.

The functional significance of "branch colonies" in H. americanus remains uncertain. As Wesson (1939) demonstrated experimentally, they do not result from mere mechanical crowding in the "primary colonies." Moreover, our observations confirm those of previous investigators in indicating that queenright americanus colonies tend to be quite small, The branch colonies do serve as a source of surplus males which might be essential to insure the insemination of all americanus queens. However, this possibility seems unlikely since "primary colonies" produce large numbers of males and since both $H$. canadensis and $H$. sublaevis appear to get along without "branch colonies." Indeed, since "branch colonies" often occur within less than a meter of queenright colonies from which they may well have arisen, it is hard to understand why raiding competition between a "primary colony" and its "branches" would not interfere with "primary colony's" capacity to exploit host-species resources. However, such competition might be minimized by the fact that americanus raiders kill very few host-species adults in their raids and the tendency of americanus colonies to rear host-species queens and males in their nests and then apparently to permit these individuals to go out on nuptial flights (Alloway, in press). These relatively nondestructive characteristics may permit dense americanus populations to survive without depleting host-species resources.

However, perhaps the best hypothesis regarding a possible adaptive advantage for the "branch colony" system in americanus arises if we suppose that the raiding range of each americanus nest is quite restricted. Thus, the formation of "branch colonies" at the periphery of the range of a "primary colony" may greatly expand the range of action of a "primary colony" and its "branches."

However, these interpretations are highly speculative. Further detailed field work is needed to work out the spatial relationship between americanus "primary colonies" and their "branches." In addition, a combined set of laboratory and field studies is needed to determine the means by which branch colonies are formed and 
to test our hypothesis that all Harpagoxenus queens and workers produced in "branch colonies" are derived from larvae taken from "primary colonies."

\section{SUMMARY}

During the summer of 1977 , we collected numerous colonies of the slave-making ant Harpagoxenus americanus in southern Ontario and northern Ohio. The numbers of dealate Harpagoxenus queens, intermorphs, and workers were recorded; and the production of young Harpagoxenus workers and sexuals were observed in 41 colonies. Some of the Harpagoxenus queens, all the intermorphs, and most of the Harpagoxenus workers were dissected to determine the structure and function of their reproductive organs. The queens, intermorphs, and most of the workers have 6 ovarioles. However, since only alate and dealate full queens have a spermatheca, they are the only individuals that can be inseminated. Thus, no true ergatoid queens exist in $H$. americanus. Nevertheless, many workers have functional ovaries and lay eggs, sometimes even in queenright colonies. We found 3 incipient colonies, 13 queenright colonies, and 23 "branch colonies" that lacked a dealate queen but contained one or more fully or partially fertile workers. Younger "branch colonies" produce males, queens and workers, supposedly from larvae of their "mother colony," older "branch colonies" only yield males. The significance of this population structure is discussed.

\section{Literature Cited}

Alloway, T. M.

[1978] Raiding behaviour of two species of slave-making ants, Harpagoxenus americanus (Emery) and Leptothorax duloticus Wesson (Hymenoptera: Formicidae). Animal Behaviour, in press.

BUSCHINGER, A.

1973. The role of daily temperature rhythms in brood development of ants of the tribe Leptothoracini (Hymenoptera: Formicidae). In: Effects of Temperature on Ectothermic Organisms. Ed. W. Wieser, Springer Berlin-Heidelberg-New York, pp. 229-232.

1975. Eine genetische Komponente im Polymorphismus der dulotischen Ameise Harpagoxenus sublaevis. Die Naturwissenschaften 62: 239.

[1978] Genetisch bedingte Entstehung geflügelter Weibchen bei der sklavenhaltenden Ameise Harpagoxenus sublaevis (Nyl.) (Hym., Form.). Ins. soc., in press. 
Buschinger, A. And T. M. Alloway

[1978] On caste polymorphism of Harpagoxenus canadensis M. R. Smith. Ins. soc., in press.

BUSCHINGER, A. AND U. WINTER

1978. Echte Arbeiterinnen, fertile Arbeiterinnen under sterile Wirtsweibchen in Völkern der dulotischen Ameise Harpagoxenus sublaevis (Nyl.) (Hym., Form.). Ins. soc. 25: 63-78.

Creighton, W. S.

1927. The slave raids of Harpagoxenus americanus. Psyche 34: 11-29.

1929. Further notes on the habits of Harpagoxenus americanus. Psyche 36: 48-50.

1950. The ants of North America. Bull. Mus. Comp. Zool., Harvard, 104: $1-585$.

Sturtevant, A. H.

1927. The social parasitism of the ant Harpagoxenus americanus. Psyche 34: 1-9.

Wesson, L. G.

1939. Contributions to the natural history of Harpagoxenus americanus Emery (Hymenoptera: Formicidae). Amer. Ent. Soc. 65: 97-122. 

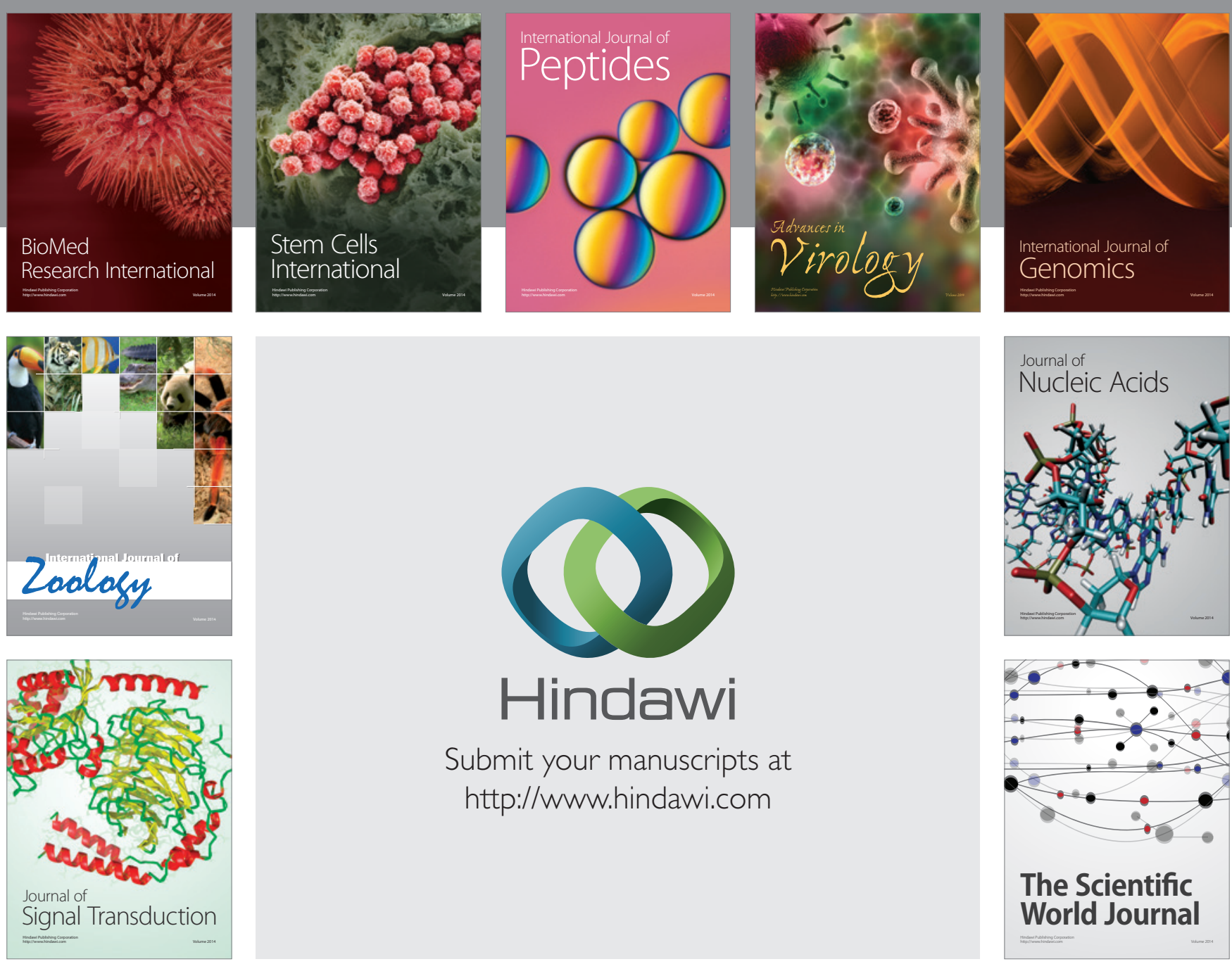

Submit your manuscripts at

http://www.hindawi.com
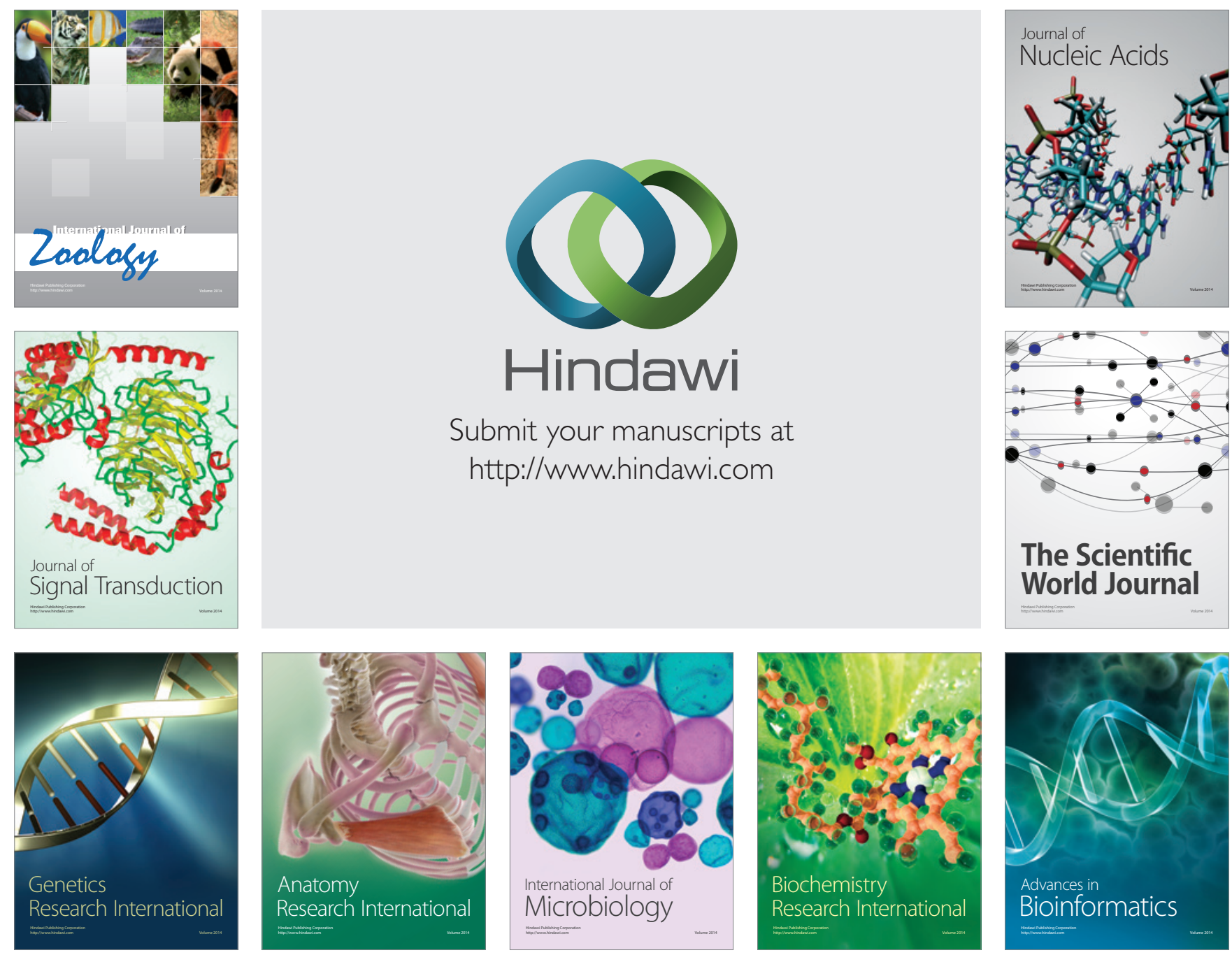

The Scientific World Journal
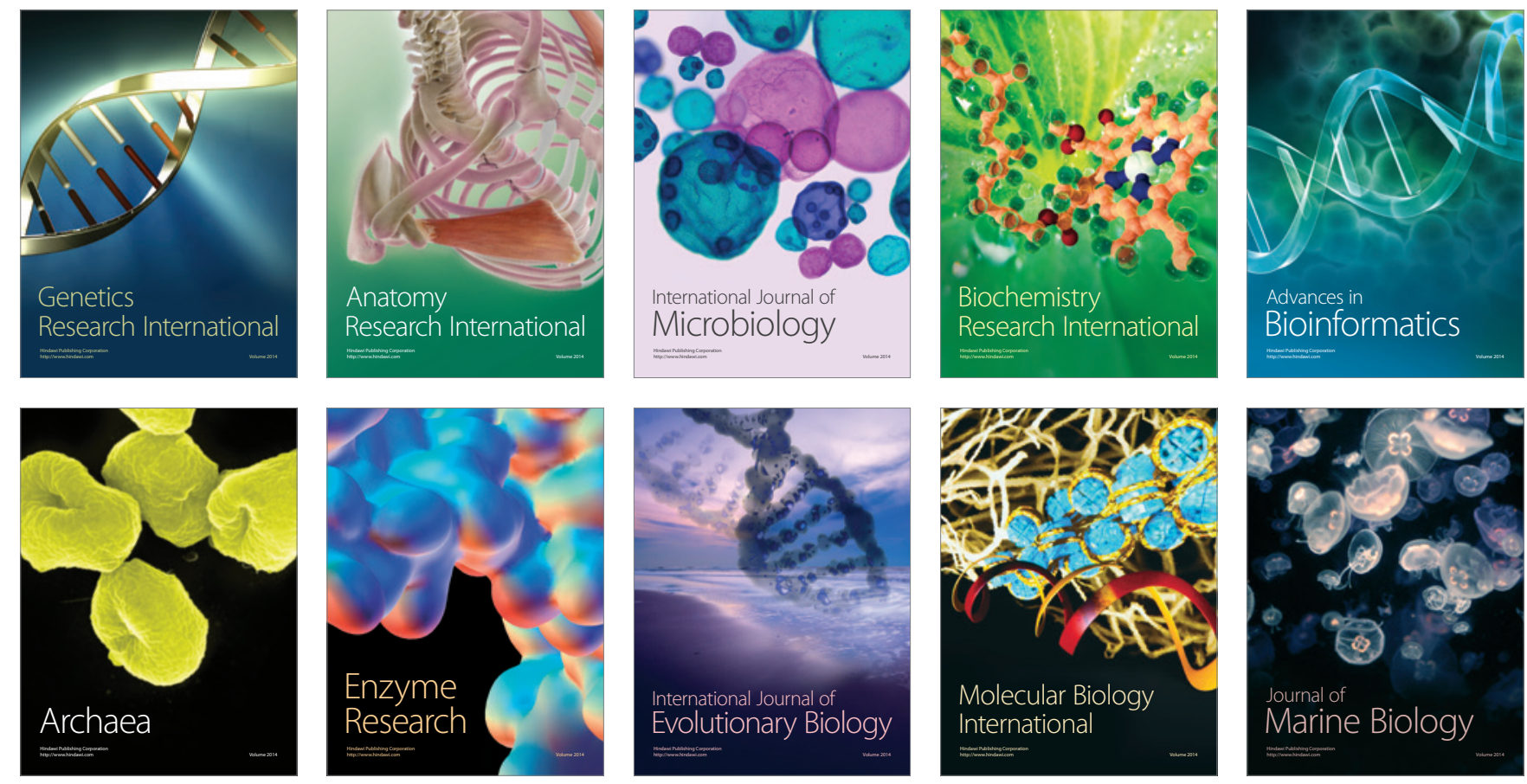